${ }^{4}$ British Medical fournal, 1974, 3, 297.

5 Hall, A P, British Medical fournal, 1976, 1, 323

6 World Health Organisation, Information on Malaria Risk for International Travellers, Weekly Epidemiological Record, 1973, 48, 25.

7 World Health Organisation, Information on Malaria Risk for International Travellers, Weekly Epidemiological Record, 1976, 51, 181.

${ }^{8}$ Barrett-Connor, E, Annals of Internal Medicine, 1974, 81, 219.

${ }^{9}$ Macdonald, G, British Medical fournal, 1965, 2, 229.

10 Ravault, M P, Fournal de Médecine de Lyon, 1965, 46, 1391.

11 François, J, and Becker, L de, Annals Oculistique, 1965, 198, 513.

12 Appleton, B, Wolfe, M S, and Mishtowt, G I, Military Medicine, 1973, 138, 225.

13 Taylor, J, British Medical Fournal, 1968, 3, 805.

14 Pearlman, E J, and Hall, A P, Annals of Internal Medicine, 1975, 82, 590.

15 Lucas, A O, et al, Transactions of the Royal Society of Tropical Medicine and Hygiene, 1969, 63, 216.

${ }^{16}$ Laing, A B G, Bulletin of the World Health Organisation, 1970, 43, 513.

17 O'Holohan, D R, and Hugoe-Matthews, J, Southeast Asian fournal of Tropical Medicine and Public Health, 1971, 2, 164.

18 Lewis, A N, and Ponnampalam, J T, Annals of Tropical Medicine and Parasitology, 1975, 69, 1.

\section{The stricken}

In March this year ${ }^{1}$ we reviewed the consequences of acute strokes, which may be expected to affect up to 400 people each year in a district with population of 250000 . Many die, but about 200 survive the first six weeks. What happens to these survivors?

The ten-year follow-up study in Denmark by Marquardsen ${ }^{2}$ of 150 men and 257 women who had recovered from strokes showed that the median survival time was less than four years. Associated heart failure greatly increased the mortality rate; so too did hypertension, especially in those under the age of 70 . Two-thirds of the patients without cardiac failure or hypertension survived five years; one-third of those with only one of these factors survived; but only one-sixth with both factors lived out the five years.

That is the natural history after stroke. Next we should ask whether survivors' needs are met and to what extent. Now that the NHS has been in existence for 28 years it is perhaps surprising that so few studies have been carried out in England on this large group of handicapped and often dependent people, though we have the excellent accounts by Adams $e \mathrm{al}^{3}$ of their work in Northern Ireland. A more recent report from Glasgow by Isaacs, Neville, and Rushford ${ }^{4}$ concentrated on the social consequences of stroke. They described 29 survivors followed for three years or until death from an original group of 76 patients with severe strokes who had been admitted to a special rehabilitation ward. Eleven of the 29 died in the course of the three years. The sample is small, but large enough to indicate notable gaps in the aftercare provided-deficiencies that are probably widespread in Britain.

Of the 29 survivors discharged, 18 were visited by the general practitioner in the first three months, but only three were still visited in the second year. Only seven of 25 patients had a home help in the first six months and only six had a district nurse, though after three years 10 of the 18 survivors had both. Domiciliary physiotherapy was recommended for 17 but eight received no treatment.

Before admission 11 patients had been in full-time employment and eight had been occupied in full-time household duties. After discharge none returned to work and only three did some household work. Eight never left their houses for a year. Only three managed a daily unaccompanied walk. None went out by public transport, none to the hairdresser or place of entertainment. Nine claimed attendance allowance; two were paid in full and four for night attendance only.
What was the effect of all this on their outlook and morale, the effect of the handicap itself, and the effect of sudden enforced retirement from work and the companionship which work affords? Happily married patients were well supported by their spouses in spite of difficulties in home management caused by irritability, frustration, consequent aggressiveness, and feelings of depression. Some refused to eat, some were messy, some voracious. Some deposited urine and faeces in inappropriate places. In recommending that more could be done for the survivors of stroke Isaacs et al specified in particular the greater use of day hospitals and the formation of stroke clubs with or without the help of the Women's Royal Voluntary Service. We also need greater awareness by all concerned for the aftercare of stroke patients and easier access to physiotherapy, occupational therapy, speech therapy, and the other services developed in geriatric and other day hospitals. Day hospitals could well become the focal point of rehabilitation in the community. This aim has been embodied in the new units constructed to DHSS design in the West Midlands and elsewhere, but many, many more are needed.

1 British Medical fournal, 1976, 1, 541.

2 Marquardsen, J, Age and Ageing, 1975, suppl, p 41.

${ }^{3}$ Adams, G F, Cerebrovascular Disability and the Ageing Brain. Edinburgh, Churchill Livingstone, 1974.

4 Isaacs, B, Neville, Y, and Rushford, I, Age and Ageing, 1976, 5, 188.

\section{Low oestrogen oral contraceptives}

In 1969 the Committee on Safety of Medicines recommended that the maximum oestrogen dosage in oral contraceptives should be $50 \mu \mathrm{g}$ per day. Two oestrogens are used in oral contraceptives-ethynyl oestradiol and its 3-methyl ether, mestranol. Ethynyl oestradiol is more potent and more popular than mestranol, which first appeared as a more or less accidental contaminant of the progestogen element in oral contraceptives. In some newer preparations the content of ethynyl oestradiol has been reduced to as low as $30 \mu \mathrm{g}$ and even $20 \mu \mathrm{g}$, which appears to be the smallest amount compatible with the desired biological activity.

After six years of low-oestrogen oral contraceptives enough data have accumulated for the position to be assessed. Of course the reason for the low oestrogen was to reduce the incidence of untoward side effects, particularly thromboembolism. The project by the Royal College of General Practitioners ${ }^{1}$ suggests that low-dose oestrogen has reduced the incidence of thrombosis by about $25 \%$. Nor has the reduction in oestrogen content been accompanied by a notable decline in their contraceptive efficiency. A recent study ${ }^{2}$ showed an uncorrected pregnancy rate of 0.16 per 100 woman years. The same study also showed that, as expected, the incidence of breakthrough bleeding is higher on low-dose oestrogens, though at $5 \cdot 2 \%$ it has not proved a serious obstacle to their use.

Even when the oestrogen content is reduced to as little as $30 \mu \mathrm{g}$ of ethynyl oestradiol per day the main basis of the contraceptive action is still by suppression of ovulation. A recent investigation ${ }^{3}$ showed that plasma $\mathrm{FSH}$ levels are depressed and that the midcycle surge of $\mathrm{LH}$ is abolished. The contraceptive efficiency may owe something to changes in cervical mucus induced by the progestogen, which prevent sperm penetration, but a failure to ovulate and depressed 